\title{
Meninos do Cense: Práticas e discursos de inclusão/exclusão
}

Raquel Ribeiro Moreiral

Résumé: Cette étude vise à étudier les modes de détermination et de traitement d'adolescents internés pour avoir été en conflit avec la loi. À cette fin, nous travaillerons avec les constructions imaginaires que les employés d'un centre socio-éducatif font sur l'adolescents admis lá, en notant la façon de construire les processus d'identification et de stigmatisation conséquente des jeunes contrevenants. Ainsi, nous sommes à la recherche pour le traitement des déterminations historiques de l'identité d'une construction particulière, c'est à dire nous avons affaire à la construction des positions de sujets. Ainsi, les images qui sont ensuite adolescente admise par le personnel du centre, comme positions de sujet discursivement significatives au sein d'une donnée FD, sont aussi construits à partir de l'image qu'ils ont de l'institution, la mise, tandis que l'état idéologique de sujet affaiblis et d'institution rédemptrice. Mots-clé: imaginaire, détermination du sujet, adolescentes internés

Resumo: Este trabalho tem como objetivo de pesquisa os modos de determinação e de tratamento de adolescentes em conflito com a lei internados. Para tanto, trabalharemos com as construções imaginárias que os funcionários de um centro de socioeducação fazem dos adolescentes ali internados, observando como se constroem os processos de identificação, e consequente estigmatização, dos jovens que infracionaram. Com isso, estamos procurando tratar das determinações históricas na construção de determinada identidade, ou seja, estamos tratando da construção de posições-sujeitos. Desse modo, as imagens que se fazem, então, do adolescente internado, pelos funcionários do Centro, como posições de sujeito discursivamente significativas no interior de determinada FD, se constroem também a partir da imagem que estes têm da instituição, configurando, ao mesmo tempo, a condição ideológica de sujeito debilitado e de instituição redentora.

Palavras-chave: imaginário, determinação do sujeito, adolescentes internados. 


\section{Para Contextualizar a pesquisa}

Trabalhar com excluídos, seja da ordem que for, requer a necessidade de mobilizar conceitos imbricados na ordem histórica, política, ideológica e social do real, uma vez que entender como se constitui o sujeito excluído só se faz possível a partir de um olhar politicamente comprometido, no qual seja possível apreender os sentidos, observando-se sempre que esses sentidos não se constroem na estagnação, na transparência ou na mera observação da sociedade. É por isso que, inicialmente, já justificamos a fundamentação deste trabalho na Análise do Discurso, pois, acreditamos que, como uma teoria do campo político, de acordo com Courtine (2006), a AD possui as bases que nos possibilitam empreender análises imbricadas nas ordens histórica e ideológica, essenciais para a construção de sentidos.

Os adolescentes em conflito com a lei internados, sujeitos da nossa pesquisa, constituem-se de adolescentes entre 12 e 21 anos, que se encontram cumprindo a medida disciplinar mais severa do Estatuto da Criança e do Adolescente (ECA), a internação, que se aplica a adolescentes reincidentes ou sentenciados por um crime grave, como tráfico de drogas, latrocínio e homicídio. Tais sujeitos interessam-nos a partir do momento em que os entendemos como pessoas em desenvolvimento que precisam muito mais de orientação e educação do que punição e correção. As instituições de tratamento desses adolescentes, no país, são historicamente marcadas por abusos de diversas ordens, assim como pela privação - além da privação de liberdade - de direitos mínimos regidos pela constituição brasileira, muitas vezes já negligenciados e/ou negados a esses meninos desde muito cedo. Tidas como "celeiros do mal", na maioria das vezes as instituições de "correção" proporcionam aos adolescentes a vivência mais intensificada do crime e da marginalização, acrescendo à marginalização da pobreza e da baixa escolaridade, das quais muitas vezes esse menino já é vítima, aquela da institucionalização. "Meninos da Febem", como muitas vezes são chamados, mesmo não havendo mais Febens desde a década de 90, esses adolescentes são estigmatizados, generalizadamente, como criminosos de alta periculosidade que precisam urgentemente de leis mais precisas e menos 'benevolentes', uma vez que, sob esse prisma, eles são constantemente privilegiados por sua condição, condição que normalmente é associada a uma violência ainda maior, pois adolescentes são instáveis e inconsequentes.

Na contramão, então, desta intensificação na campanha de diminuição da maioridade penal, procuramos entender como as instituições de cumprimento da medida de internação portam-se perante todas as reformulações apontadas desde 1990, ano de implantação do Estatuto da Criança e do Adolescente. Para isso, escolhemos um Centro de Socioeducação do interior do Paraná. Nesta instituição, os meninos fazem todas as atividades em grupos de 5, sempre 'vigiados' por funcionários, chamados de educadores sociais, que são os responsáveis pelos deslocamentos, refeições, banhos e cumprimento das regras da instituição. É justamente sobre essas regras e seus cumprimentos que queríamos atentar. Pois, nos parece que, de acordo com a conjuntura social em que esse menino se encontra, um trabalho 'intra-muros', que não se estenda à vivência social e cultural dos adolescentes e familiares, não nos parece conseguir, de fato, realizar a socioeducação tão apregoada, a não ser que este trabalho se baseie na alienação sócio-histórica e seus resultados não passem de mascaramentos midiáticos para justificar investimentos públicos. O Centro investigado possui um índice de reincidência que gira em torno de $78 \%$ a $82 \%$, estatística mensurada pelos próprios funcionários, o que nos aponta para sérias falhas no papel daquilo que a instituição aponta como sua missão, que é a de ressocializar o adolescente internado. Nossa análise, além da alienação sócio-histórica do trabalho realizado ali dentro, o qual desconsidera as contingências históricas, políticas e sociais que constituem as reais condições de 
existência desses meninos ${ }^{2}$, é a de que o Centro (assim como outras instituições) pauta-se, ainda, sob a violência com o intuito de correção e adequação das atitudes e comportamentos destes adolescentes. Não mais uma violência física, apesar de ainda existir, justificada pela necessidade de segurança dos próprios internos e dos funcionários, mas essencialmente uma violência simbólica, travestida de regras e normas disciplinares que servem, muitas vezes, para humilhar, subjugar e até assediar (abuso moral) os adolescentes que insistem em "não se comportar da forma esperada", isto é, serem obedientes, cordatos e inexpressivos.

Foi, portanto, com o intuito de observar como se estabelece esta relação de estigmatização e violência no referido Centro que tratamos de construções imaginárias neste trabalho, pois estamos querendo tratar de determinações históricas na construção de determinada identidade, ou seja, da construção de posições-sujeitos. Essas determinações históricas (e imaginárias) serviram como base para que nós “avaliássemos”, como um efeito ideológico, as atitudes e comportamentos tanto dos adolescentes internados quanto dos funcionários do Centro, observando suas inscrições, "semi"-voluntariamente, ou não, em determinada posição-sujeito (que também pode ser no plural), de determinada formação discursiva, assim como as construções imaginárias que pautassem a avaliação que estes sujeitos fazem uns dos outros.

Essas construções imaginárias apontam para efeitos que são mobilizados na construção dos modos de determinação dos sujeitos: determinação do eu e determinação do outro. Nesse espaço, constroem-se as relações entre os sujeitos, e é aqui que se desenrola o rol de designações de um - grupo de - sujeito(s): menor, delinquente, trombadinha, pivete, adolescente, sujeito de direitos e etc... Todas essas designações mobilizam saberes e domínios diferenciados, e não se trata de simples escolhas lexicais, variações de estilo e muito menos de meros nuances semânticos, são atributos que, em seus apagamentos ou explicitações, atestam posições ideológicas. Portanto, não há como desprender o político do simbólico, ou seja, não podemos falar de construções imaginárias, determinação do sujeito e muito menos de filiação a uma formação discursiva, sem levarmos em consideração as posições ideológicas que constituem os sujeitos, os discursos e as instituições.

Podemos perceber, desse modo, ao analisarmos os documentos e legislações sobre esse sujeito, que suas designações variam de delinquente (sinônimo de pobre e marginalizado), que precisava ser vigiado e retirado do convívio social, à adolescente, sujeito de direitos, que precisa ser amparado e protegido, mas que, ainda de acordo com a lei, precisa ser segregado em uma instituição fechada. Espécie de câncer social, o "menor", como ainda é fortemente designado, especialmente pelos meios de comunicação, aparece, segundo Haroche (1992), como efeito de um espaço lacunar, que serve muito mais para sua não determinação do que para qualquer outra coisa. Simbiose do que mais se admira - a infância, a ingenuidade, o desabrochar - e, ao mesmo tempo, do que mais se repudia - o crime, a violência, o descontrole - a criança marginalizada, e especialmente o adolescente, aparece como aquele sem lugar: não pode ser preso, mas não pode ficar na rua; é um ser em desenvolvimento, mas é um marginal mirim; busca-se o protagonismo juvenil, mas ele não tem/teve nenhuma oportunidade. Ao não ser isso nem aquilo, ou por ser tudo ao mesmo tempo, o adolescente inspira sentimentos diferenciados, que aparecem sob as marcas de piedade, afetação, comiseração, preocupação, de indiferenciação e de temor.

2 Fazemos referência à exclusão, ao abandono, à desestrutura emocional e financeira dos pais, à extrema pobreza, à falta de cultura, educação, entre outros. 
Partindo do reconhecimento dessa(s) concepção(ões), então, nos debruçamos sobre o imaginário dos funcionários do Centro de Socioeducação a respeito dos adolescentes ali internados. Observamos um alinhamento entre a defesa da instituição como modelo de educação e garantia dos direitos dos adolescentes, ao mesmo tempo em que se percebe a recorrência à especialização (à área de formação de cada profissional) na determinação do adolescente internado. Assim, esses jovens terão ou suas carências/deficiências sócio-econômicas enfatizadas (para os assistentes sociais), ou serão apontados como fruto - os adolescentes e seus familiares - de distúrbios e/ou desarranjos emocionais (para os psicólogos), ou ainda como resultado de deliquência e marginalização (fato observado por educadores sociais).

Todavia, a 'crença' na função benéfica do Centro de Socioeducação sempre foi propalada, constituindo o amálgama das falas ali escutadas. É por isso que o conceito de imaginário nos é muito caro neste trabalho, uma vez que para entender os sujeitos envolvidos nesta pesquisa (especialmente o adolescente em conflito com a lei, mas não somente ele, e aí se torna essencial compreender quem são os profissionais que com ele trabalham), precisaremos, também, entender "tudo [o] que serve para formar (valores, normas, instituições, ideias e materiais pedagógicos) [e que] engendra ipso facto um magma de representações e de significações imaginárias que se insere na práxis educativa e em suas realizações." (BARBIER, 1994, p.15)

Nesta perspectiva, não nos interessa a visão de imaginário como a de uma oposição ao real, ou como lapso do racionalismo, ou ainda como evento da ordem da fantasia, da pura invenção ou da representação "no espírito". Não estamos falando das peças teatrais; estamos nos referindo ao todo de significações que é construído e permeado nas e pelas relações sócio-discursivas, todo esse que se insere vividamente (e não como mascaramento) no nosso cotidiano.

É somente nessa perspectiva que podemos perceber a práxis, mencionada acima por Barbier, como o alicerce no qual se tecem os imaginários. É somente sob esse conceito de práxis, como forma de conhecimento da história encarnada nas formas de vida social efetiva, que podemos reconhecer quem é que fala, isto é, um ser histórico, e de quem ele fala. Castoriadis (1982) apresenta esta práxis com uma atividade consciente que se apóia sobre um saber, mas um saber que é sempre fragmentário e provisório, já que:

É fragmentário, porque não pode haver teoria exaustiva do homem e da história; ele é provisório, porque a própria práxis faz surgir constantemente um novo saber, porque ela faz o mundo falar numa linguagem ao mesmo tempo singular e universal. É por isso que suas relações com a teoria, a verdadeira teoria corretamente concebida, são infinitamente mais íntimas e mais profundas do que as de qualquer técnica ou prática 'rigorosamente racional' para a qual a teoria não passa de um código de prescrições mortas não podendo nunca encontrar o sentido daquilo que maneja. (1982, p.95)

Assim, nem a práxis pode ser redutoramente determinista, nem os saberes totalizados e transparentes. Portanto, também não o são os sujeitos e suas significações imaginárias. É no entrelaçamento do social-histórico e do simbólico que a práxis, os saberes, os sujeitos e as significações imaginárias amalgamam-se e passam a construir e a ditar identidades - psicólogos, assistentes sociais, juízes, educadores, adolescentes - e posições - profissional, funcionário, excluído, marginal. No jogo de determinações entre essas diferentes identidades e posições, marcam-se numerosas significações imaginárias que não são somente adicionadas ao caráter "inter-subjetivo" deste ou daquele, mas que 
materializam-se e instituem-se - devido a sua rede de significações - ao mesmo tempo que são materializadas e instituídas, pois elas atuam justamente na "união" e na "tensão" (voltamos a repetir, ao mesmo tempo, e muitas vezes como mero efeito, tanto uma quanto a outra) do corpo social-histórico.

Por isso, nos parece essencial cercar-nos de uma gama de elementos fundantes e transformadores do processo de simbolização desse adolescente em conflito com a lei, observando como esse imaginário social fragmentado se institui a partir dos conjuntos de interpretação, das experiências individuais e coletivas, das relações com as leis e com os valores sociais aceitos/impostos, e como tudo isso se dá em relação a esse sujeito. Ferreira e Eizirik (1994) reforçam tal ideia afirmando que, como rede de sentidos, o imaginário social matricia, sob diversos aspectos, a conduta coletiva, na medida em que valores, normas e interdições, como códigos coletivos, são internalizados/apropriados pelos agentes sociais. E isso, é claro, não se dá a partir de uma "criação" de determinado segmento social, em uma atitude maquiavélica de formar "ideias" ou "condutas", nem tampouco resulta da adição e/ou justaposição dos anseios e desejos coletivos. O imaginário social organiza e reifica práticas sociais que regulam esta mesma sociedade como instituição social, ou seja, que permitem que ela ritualize-se, hierarquize-se e que, desse modo, possa legitimar-se. As autoras acima, Ferreira e Eizirik, podem nos auxiliar nesta explicação:

"Como um sistema simbólico, o Imaginário Social reflete práticas sociais em que se dialetizam processos de entendimento e de fabulação de crenças e de ritualizações. Produções de sentidos que circulam na sociedade e que permitem a regulação de comportamentos, de identificação, de distribuição de papéis sociais. Isso é vivido de tal forma pelos agentes sociais que passa a representar para o grupo o sentido de verdadeiro." (1994, p.6/7)

É por essa razão que o imaginário de "menor"- sujeito marginalizado/marginal, que é imbuído da visão de delinquência, violência e risco social - permeia os mais diversos segmentos da sociedade. Como sistema simbólico que dialetiza sentidos de exclusão e culpa, de abandono e de desajuste, a criança e especialmente o adolescente em conflito com a lei têm criado em torno de si um imaginário de perigo e de nocividade, gerando "entendimentos" que vão desde a piedade à aniquilação . Estes entendimentos são advindos, muitas vezes, de formações e conceitos interiorizados, de crenças cristalizadas a partir da rotina do cotidiano e que, por isso mesmo, acabam naturalizando-se como práticas coletivas de segmentação, exclusão e/ou indiferença.

A seguir, nos propomos a observar os sentidos que compõem o processo de simbolização a respeito dos adolescentes em questão, refletindo como determinados "comportamentos e ações" são regulados pela cadeia de imaginários.

\section{A simbolização do assistencialismo}

Contextualizando o que dizíamos acima, os sentidos e as práticas sociais não se constroem somente a partir das decisões racionais e conscientes dos sujeitos, muito embora não possamos afirmar, de modo algum, que a consciência dos sujeitos é algo fantasioso ou mero efeito de subjetividade. Quanto a isso, apoiamo-nos em Castoriadis que afirma que "não existe nem vida, nem realidade social sem consciência." (1982, p.32). Assim como o autor, acreditamos que o homem pensa, e esse pensamento não é simplesmente a elaboração - às vezes confusa e contraditória - do que já existe e persegue o homem, é também 


\section{Conexão Letras}

a "relativização" do que é dado, ou seja, é a reflexão, "colocação à distância" e projeção para uma outra (ou não) prática. É por isso que o mesmo autor nos afirma que "a história é tanto criação consciente como repetição inconsciente.” (CASTORIADIS, 1982, p.33)

Pois bem, se não podemos dizer que os sentidos e as práticas sociais não são exclusivamente decisões conscientes do sujeito, ao mesmo tempo não significam puras imagens, simbolismos culturais e/ou fruto da imaginação individual. Há uma correlação entre os discursos, as ideologias, as instituições, os sistemas de representações coletivos e a história que aponta para a constituição daquilo que chamamos Imaginário Social; as leis sociais, de convivência e de submissão/dominação dos homens não existem autonomamente, pairando sobre os sujeitos, mas elas materializam-se em práticas sociais, históricas e ideologicamente constituídas, mas que, em si, constroem ou destroem elos, oportunizam identificações, instituem grupos, a partir de uma vivência real e, ao mesmo tempo, imaginária. É, com efeito, a constituição, em um mesmo instante, da práxis e dos modos de representação social; modos esses que legitimam a ordem social vigente e/ou apontam suas transgressões, ao mesmo tempo em que significam a prática. Portanto, quando falamos em construções imaginárias, estamos tratando de "uma complexa rede de sentidos que circula, cria e recria, instituindo/instituindo-se na luta pela hegemonia"3. Dentro da instituição por nós pesquisada, esses sentidos trabalham no embate entre os processos de real socioeducação dos meninos em conflito com a lei e o ideário coletivo, e muitas vezes reacionário, de correção e regeneração.

Essa luta pelo o que é hegemônico não se dá a partir da soma ou da justaposição dos desejos e vontades coletivos, mas da instituição de um sistema simbólico que se constrói a partir de ritos, de crenças, da linguagem, e que reflete as práticas sociais que se ajustam, contradizem, dialetizam e que permitem a regulação de comportamentos, de identificações e de distribuição de papéis sociais. Nessa distribuição, os adolescentes em conflito com a lei representam papéis diferenciados: o algoz de crimes bárbaros, para a classe média; o principal beneficiado de uma lei que gera impunidade, para a grande mídia; e o incapaz, esvaziado de todos direitos e oportunidades, para as políticas sociais e assistencialistas. Contudo, mesmo com essas diferentes determinações, a rede de sentidos que se cria em torno do adolescente aponta para um mesmo lugar: o da privação de liberdade, do silenciamento, da invisibilidade. E é isso que o imaginário social faz, arranja de tal maneira as crenças, as idéias, os saberes, que passa a representar para o grupo o sentido verdadeiro.

Assim, não importa se com a "intenção" de re-educação (como as decorrentes da legislação atual) ou de higienização social (como era possível observar nas leis de 1897 e 1942), a privação de liberdade é defendida por empresários, jornalistas, psicólogos e assistentes sociais como $a$ medida, senão ideal, mas a mais acertada, para o adolescente que infracionou; suas únicas discordâncias restringem-se ao tempo da medida.

Tal noção, a nosso ver, reforça a concepção de que a estrutura social, e suas devidas instituições, formas de estratificação e práticas, fundamentam-se e legitimam-se, também, por sistemas simbólicos, fazendo crer que as sectarizações, as exclusões e as divisões hierárquicas são 'naturais', ou na pior das hipóteses, são culpas individuais de sujeitos desajustados. Essa polarização vai depender de diversos dispositivos que vão desde a produções legais, como o Estatuto da Criança e do Adolescente, por exemplo, passando pelos modos coercitivos, como a maciça propaganda midiática para a redução da maioridade penal, chegando até às formas mais sofisticadas de formação de opinião, como determinados

3 Ferreira e Eizirik, 1994, p.6. 
cursos universitários (psicologia, assistência social, direito) e instituições de socialização (com seus devidos concursos, cursos de formação, capacitação e etc.).

A internalização dos conceitos, normas e, porque não, das interdições também, que medeiam a "conduta" coletiva, é agenciada, como uma espécie de amálgama histórico e social das interpretações e experiências dos sujeitos, pelo Imaginário Social, essa espécie de rede de sentidos que "consiste em ligar a símbolos (a significantes) significados (...) e fazê-los valer como tais, ou seja, a tornar esta ligação mais ou menos forçosa para a sociedade ou o grupo considerado." (Castoriadis, 1982, p.142)

Esse processo de simbolização não é o reflexo da realidade, mas também não é uma invenção ilusória e criativa, ele é parte do real, é seu fragmento. Por isso o Imaginário Social não é capaz só de mascarar os conflitos e tensões, como também de reforçar a dominação/ exclusão. E é por isso, também, que é fundante não só na determinação do outro, mas na determinação de si. Reforçamo-nos em Pêcheux que, ao tratar do imaginário, constrói a noção de formações imaginárias, sob a qual afirma que:

“(...) o que funciona nos processos discursivos é uma série de formações imaginárias que designam o lugar que A e B se atribuem cada um a si e ao outro, a imagem que eles se fazem de seu próprio lugar e do lugar do outro. Se assim ocorre, existem nos mecanismos de qualquer formação social regras de projeção, que estabelecem as relações entre as situações (objetivamente definíveis) e as posições (representações dessas situações)." (1997, p.82)

São a essas regras de projeção a que nos referimos quando falamos em Imaginário Social, ou seja, de formas que remetem ao campo do dizível e do indizível ao mesmo tempo, uma vez que é impossível pensar o sujeito, o discurso, as instituições e a própria práxis sem a dimensão simbólica e "sem a imagem que [os sujeitos] têm de si próprios e dos outros." "É essa imagem de si, ou seja, do funcionário do Centro de Socioeducação, e do outro, do adolescente, imbricadas em um discurso de "compensação" de debilidades e carências - no qual um é o sujeito consciente dos problemas e necessidades do outro e vem como salva-vidas e/ou redentor, enquanto o outro é uma "vítima" desorientada em uma sociedade que não the acolheu - que povoa o discurso dos funcionários da instituição referida. A contradição das condições de existência dos meninos marginalizados transforma-se, muitas vezes cinicamente, cremos, em mero contraste entre os que precisam e aqueles que têm para dar, e é aí que entra a instituição - esse lugar onde ocorrem as práticas e ritos, portanto espaço também da materialidade ideológica. É nela que se tem, é ela que oferece o que esses meninos precisam.

A fim de ilustrar as considerações acima, passamos a inserir, em nosso texto, alguns recortes obtidos em entrevistas com funcionários do Centro, entrevistas estas que integram nosso corpus de análise. Foram feitas dezesseis questões, aos funcionários, que versaram sobre funcionamento e avaliação da instituição; determinação do adolescente internado e do trabalho praticado na instituição; práticas de disciplinarização e violência, entre outras. Para o que se pretende analisar neste trabalho, selecionamos a seguinte pergunta que nos permite refletir em torno das contradições nos modos de representação dos adolescentes:

1) Descreva o funcionamento do CENSE. Para que ele serve?

Observemos a seqüência discursiva 1:

4 Cf. Ferreira e Eizirik, 1994, p.8 


\section{Sd 1}

[aqui] dá conta do processo como um todo, tem atendimento psicológico, assistente social, tem escola, o máximo de diálogo que ele não têm lá fora, então tem muito essa parte do diálogo, que falta para eles, por exemplo, os pais não são presentes no dia-a-dia deles, e aqui eles encontram essa atenção, porque aqui a gente passa pra eles, vamos supor, carinho que eles precisam, ter atenção, a gente podendo fazer, porque muitos deles às vezes querem atenção.

Essa imagem que os funcionários do Centro constroem de si, como sujeitos que suprem necessidades, e do outro, como carente de afeto, economicamente.... (mas não como sujeitos despossuídos das necessidades básicas de existências, segregados à invisibilidade, excluídos do processo de participação político-cultural, em uma espécie de mendicância social), é essencial para a "estruturação" das formações discursivas nas quais tanto a instituição, quanto os próprios funcionários se inscrevem, formações essas que, devido às especializações dos profissionais envolvidos no processo de socioeducação, apresentam-se múltiplas, mas que convergem todas em torna da condição de inferioridade (social, cultural e às vezes moral) do adolescente em conflito com a lei, ao mesmo tempo em que se colocam sob o paradigma do assistencialismo ou da desresponsabilização sócio-política quanto ao tema. Ou seja, se este (a instituição) não é mais o lugar punitivo, de exclusão e de higienização social, como se originariamente pensou e estruturou as antigas instituições para "menores"; ou ainda se este lugar não pode mais, de acordo com a lei, violar os direitos mínimos do sujeito, como o direito à educação, à alimentação, à higiene, entre outros; e se não se pode mais usar do argumento da violência física como demonstração de culpabilidade e de animalização do adolescente, pensando não mais esse sujeito como monstro social, mas como vítima de uma sociedade que não o agregou, então, se não se faz tudo isso, é porque o que se faz, de acordo com os funcionários, só pode ser bom, certo, ideal. Aliás, essa perspectiva é reforçada sob a visão paternal construída pelo funcionário, na qual somente na internação, ou seja, no cumprimento de uma medida de privação de liberdade, esses adolescentes podem encontrar o carinho, o diálogo e a atenção que necessitam, mas que não possuem em suas famílias, comunidades. Há a distorção da constituição de uma instituição punitiva (e não há como se negar isso), para a de um lugar salutar e por isso requerido ou mesmo necessário a este adolescente que "às vezes só quer atenção".

Esta condição idealista da instituição, contudo, ultrapassa a noção paternal dada por este funcionário, para alcançar um âmbito mais social, cidadão, que vê a função deste adolescente na sociedade a partir de sua possível ressocialização. Vejamos tal ideia na sd 2 que trata sobre a função do Centro:

\section{Sd 2}

O CENSE vem com o objetivo de ressocialização, ele dá uma nova oportunidade para o adolescente na sociedade, para que ele seja ator, mas de uma forma diferente, para que ele possa exercer seus direitos e também seus deveres, para que ele aprenda a conviver de uma forma diferente, não estando mais em conflito com a lei.

Acredita-se de fato que o papel da instituição é tornar esse sujeito, com as mais diversas necessidades, "apto" para conviver em sociedade, isto é, na perspectiva apontada pelo funcionário, é preciso ressocializá-lo. Percebe-se claramente, neste termo "ressocialização", um eufemismo na determinação agora da atuação e 'responsabilidade' da instituição. 
Eufemismo fruto da cartilha do politicamente correto, que trabalha com o mascaramento do preconceito e da discriminação a partir da construção de um léxico que se pretende neutro e sem inscrições histórico-ideológicas, o que não passa de ficção. Ao atrelar-se às noções de civilidade e co-participação social, a ressocialização pretende mobilizar sentidos de uma 'qualificação' desses sujeitos, uma vez que ressocializar pode ser entendido como fazer algo novamente, então entende-se que os adolescentes estavam socializados a priori, mas com o crime foram excluídos dessa sociedade. Contudo, este fato é apagado com a pena, já que ele pode socializar-se novamente. E também, decorrente desta interpretação, a ressocialização pode ser entendida como uma dupla socialização, socializar-se mais uma vez, na qual o sujeito tem mais uma chance de agir como se é socialmente esperado. Apagam-se as exclusões e os descumprimentos políticos com esses sujeitos e, em seu lugar, acentua-se a necessidade individual de adaptar-se, para que assim ele possa ser ator, não de qualquer modo, mas de uma forma diferente, sem contestações, transgressões, ciente de quais são seus direitos e deveres nesta sociedade que lhe é inóspita e/ou negligente.

Se retornarmos às questões do imaginário, veremos que o jogo simbólico construído no/pelos funcionários é o de que seu papel e o da instituição vêm no sentido de oferecer aos adolescentes o que eles não encontram no dia a dia, oportunizar a eles situações/sensações que lhes foram negadas/rejeitadas, dar-lhes uma nova oportunidade de vida. Tudo isso em um espaço paralelo, sob o efeito de a-social, a-histórico, ideal. Quer dizer, esta ressocialização se dá em um ambiente que em nada parece o cotidiano desse adolescente. Ali, hermeticamente trancado e vigiado, o adolescente não passa por certas privações que o acometem no dia a dia. Não há fome, o acesso às drogas é substituído por medicações que inibem e/ou substituem os efeitos alucinógenos, não há contato com outros adolescentes, minimizando brigas e rixas, a educação é regulada pelo currículo mínimo, trabalhando-se, desse modo, a instituição, completamente alienada (como se fosse possível dentro de uma cela) àquilo pelo qual o adolescente está passando. Ele, o adolescente, não vê o pai embriagado, não precisa lutar para se manter vivo, sua disputa por 'privilégios' se dá a partir de bom comportamento, quer dizer, ficar calado quando precisa, não desrespeitar as autoridades da instituição e não provocar confusões. Por isso estamos chamando de paralelo o espaço no qual o social - seus embates e transformações - é artificialmente criado na sociedade do "bom comportamento"; a história se vê como cronologia do tempo, pois não se trabalham as condições de existência desse adolescente e os porquês de sua 'transgressão', assim como se procuram ignorar suas necessidades políticas: como educação de qualidade, trabalho, desintoxicação e etc... Ou seja, em nada a rotina da instituição lembra o cotidiano na sociedade, fato não questionado pelo Centro que, ao contrário, esforça-se em apontar que há ali tudo o que lhes (aos adolescentes) falta 'lá fora'. É importante ainda frisar que os meninos seguem (e precisam para sustentar esse imaginário de espaço educativo idealizado) um organograma militarmente distribuído em horas específicas para tomar banho, comer, estudar, recrear, dormir e etc. À primeira vista, esta 'disciplina' pode parecer a de outro adolescente qualquer que vive com sua família, contudo, quando dizemos 'rotina', queremos salientar os tratamentos dados a estes adolescentes, que precisam comer em seus alojamentos (celas com $2 \mathrm{~m}^{2}$ ); que estudam em celas trancadas, com cinco alunos de cada vez, vigiados por 'educadores sociais'; adolescentes que passam por "deslocamentos", uma espécie de estratégia policial para levá-los de um lugar a outro: sempre no número máximo de cinco, com no mínimo dois educadores sociais, e para o qual os adolescentes devem andar com as mãos para trás e com a cabeça sempre abaixada. Diferentemente, então, da 'rotina' de qualquer adolescente, todas essas regras, relacionadas a práticas coercitivas e 
penalizantes, atuam como efeitos de acentuação da marginalidade e da delinquência na construção de um imaginário social, imaginário esse que vê no adolescente internado um sujeito perigoso, transgressor, violento e ameaçador. Decorrem daí justamente os sentidos de enquadramento, punição e subserviência instados na e pela instituição, que a balizam para esse mesmo imaginário social construído a partir, de um lado, do medo, e de outro, da necessidade de vingança e aniquilação.

Todas essas práticas ritualizadas que engendram e são engendradas por uma rede de significações sobre o que é educar, re-educar, recuperar e etc, levam-nos a questionar como uma instituição nesses moldes pode dar uma nova oportunidade para o adolescente na sociedade. Além disso, insistimos: como se ressocializa alguém excluído e excluindo-o da sociedade? O Centro não faz parte da sociedade? Esse "aqui dentro" versus o "lá fora" existe como um processo real ou fictício? É possível estar fora da sociedade? As instituições, e essa em particular, não estão a serviço de determinada concepção de sociedade organizada, fruto de embates ideológicos-históricos? Apagar todos esses questionamentos é uma necessidade na sustentação do ideal das instituições, para que possam tornar-se hegemônicas, proclamando-se, como nesse caso, a instituição como espaço educativo de construção de cidadãos. Essa visão universalista de cidadão, aquele 'ator social, que exerce direitos e deveres', também é fundamental na sustentação de uma visão positivista, uma vez que o "fracasso" ( a reincidência, o abandono escolar e a não profissionalização exterior à instituição e até a morte desses meninos) é responsabilidade individual desse sujeito que não "aproveitou" as oportunidades oferecidas pela instituição; como os próprios meninos afirmaram por diversas vezes em suas entrevistas, repetindo o discurso muito bem aprendido, 'só muda quem quer'.

Castoriadis (1982, p.159) define instituição como uma rede simbólica, socialmente sancionada, onde se combinam, em proporções e em relações variáveis, um componente funcional e um componente imaginário. O componente imaginário no Centro é o de um lugar positivamente estruturado, baseado no diálogo, na atenção, no carinho, na educação e na emancipação. Já o componente funcional é a privação de liberdade, é o dentro destituído do fora ${ }^{5}$ e, nessa concepção, a punição dos atos cometidos. É, existencialmente, sua caracterização como instituição total. De acordo com Goffman (1975), uma instituição total pode ser definida como um local de residência e trabalho, onde um grande número de indivíduos com situação semelhante, separados da sociedade mais ampla por considerável período de tempo, levam uma vida fechada e formalmente administrada. Essa tendência ao fechamento se dá devido seu caráter total simbolizado por barreiras às relações sociais com o mundo externo, por meio de proibições à saída, por exemplo, que estão incluídas no esquema físico de portões de ferro, muros altos, arame farpado, câmeras e portas eletrônicas - estrutura da Centro - que separam o internado da sociedade em um grau máximo de restrição. Uma instituição como essa, total, não permite muito contato entre o internado e o mundo exterior, até porque o objetivo é excluí-lo completamente de seu "mundo originário", a fim de que o internado absorva totalmente as regras internas, por ele inobservadas quando estava livre, evitando-se, assim, comparações consideradas prejudiciais ao seu processo de "aprendizagem" e de "ressocialização". De fato, este tipo

5 Isso se torna bem evidente na fala dos funcionários, quando eles reclamam das "consequências" da visita familiar. Os meninos ficam bastante agitados com as notícias que as famílias trazem "de fora", como problemas familiares, afetivos ou do trabalho, recados ou ameaças de pessoas envolvidas no crime, cobranças sobre a conduta do menino e etc.... Os funcionários reúnem-se com os familiares e pedem para que não se tragam notícias negativas da "rua”, pois isso interfere no processo de 'recuperação' dos adolescentes. 
de instituição é organizado para proteger a "comunidade" contra perigos e ameaças que estes adolescentes, por exemplo, representam, por isso o bem-estar destes últimos não se apresenta, muitas vezes, uma preocupação central.

Cumpre-nos apontar, também, que, nas instituições totais como o Centro, busca-se a 'transformação dos indivíduos', atuando-se como um aparelho repressor que intenciona, ao encarcerar o sujeito, 'retreiná-lo', torna-lo dócil, ajusta-lo, reproduzindo, em muitos casos, a própria violência cometida por este, tornando a pena, por vezes, tão horrenda quanto o crime cometido ${ }^{6}$.

É sobre isso que fala Goffman (1975, p.152) quando afirma que os participantes de uma instituição total podem ser induzidos a cooperar através de ameaças ou de castigos se não fizerem algo, que é o que acontece com as "medidas disciplinares" no CENSE. A noção de que um castigo pode ser um meio eficiente para provocar a aceitação desejada, de acordo com o autor, exige suposições sobre a natureza humana diferenciadas daquelas que explicariam um efeito motivador, por exemplo, reforçando-se a ideia que se tem da instituição como lugar muito mais voltado para a punição formal do que de transformação social. Instaura-se, assim, a questão da contradição, ou seja, apesar das instituições totais assumirem um compromisso de transformação social, dentro de uma sociedade capitalista, na maioria das vezes sua atuação delimita-se na punição formal e na 'castração' moral e psicológica dos sujeitos que não se enquadram nos modelos desejados. O medo do castigo, por exemplo, altamente difundido nas instituições totais, pode ser adequado para impedir que o indivíduo realize determinados atos ou que deixe de realizá-los, quer dizer, é a mesclagem da pedagogia e da terapia do medo na tentativa de estruturação de sujeitos adequados para esta sociedade que aí se apresenta.

Desse modo, do mesmo jeito que toda instituição tem uma disciplina de atividades, nos afirma Goffman, ela também apresenta uma disciplina do ser, quer dizer, ela impõe a obrigação de se ser uma determinada pessoa, com um determinado caráter que deve habitar um determinado mundo/sociedade. Assim, apesar destas instituições totais afirmarem sua preocupação com a reabilitação dos sujeitos internados, na maior parte das vezes elas não passam de "estufas para mudar pessoas" (GOFFMAN, 1975, p.22), experimentos sócio-ideológicos na busca de intimidação, retribuição do medo e da humilhação e da reforma. Para Goffman:

Quase sempre, muitas instituições totais parecem funcionar apenas como depósitos de intenados, mas usualmente se apresentam ao público como organizações racionais, conscientemente planejadas como máquinas eficientes para atingir determinadas finalidades oficialmente confessadas e aprovadas. Já se sugeriu também que um freqüente objetivo oficial é a reforma dos internados na direção de algum padrão ideal. Esta contradição, entre o que a instituição realmente faz e aquilo que oficialmente deve dizer que faz, constitui o contexto básico da atividade diária da equipe dirigente. $(1975$, p.69,70)

É isso que observamos na instituição, quer dizer, devido à estruturação do Centro e à sectarização das atividades e responsabilidades, entrevemos contradições entre aqueles componentes imaginário e funcional de que falávamos acima. Contradição entre o que se faz e o que se diz fazer na medida em que, por exemplo, os educadores sociais, nome

6 Exemplos de barbaridades cometidas contra indivíduos presos podem ser vistos em diversos relatórios de órgãos nacionais e internacionais sobre direitos humanos. Como exemplo temos o relatório da Comissão Teotônio Vilela, de 1986; o relatório da Unesco - sobre o estado de paz e a evolução da violência, de 2002; ou ainda uma reportagem especial da revista Caros Amigos, de setembro de 2004. 


\section{Conexão Letras}

politicamente correto para os agentes responsáveis pela segurança da unidade (preocupação primordial da instituição), e ao desempenharem suas funções, não permanecem tempo suficiente com os adolescentes; ou então da equipe técnica, composta basicamente por assistentes sociais e psicólogos, que faz um atendimento semanal (de quarenta minutos, para os psicólogos) ou quinzenal (assistentes sociais) com os meninos; isto é, como e quando se dá toda essa troca de afeto, carinho e diálogo por eles defendida? Quando os meninos infringem as normas da instituição (quando brigam entre si, desrespeitam um funcionário, falam mais alto, trocam alimentos e/ou outros pertences, mudam as coisas de lugares e etc...), eles 'pegam' medida disciplinar, que consiste em ficar em seus alojamentos, sem sair para qualquer atividade (a não ser o solário - "banho de sol" - exigido em lei), sem coberta, colchão ou qualquer outro item; questionamo-nos em que sentido essa espécie de "privação de liberdade da privação de liberdade" pode exercer um papel educativo na emancipação desses sujeitos? Como conciliar, por exemplo, o que temos nas sd 3 e sd 4, ditas, respectivamente, por uma assistente social e por uma psicóloga, ao serem indagadas sobre o funcionamento da instituição:

\section{Sd 3}

... vai buscando o que o menino precisa, e o serviço social também, o objetivo de vida dele, tentar construir... que ele tenha sonho, porque às vezes ele vem para cá e não tem.

\section{Sd 4}

O Centro serve para ajudar esses meninos... Aqui a gente percebe que as relações interpessoais deles são bastante debilitadas, então a gente trabalha nesse sentido.

E as seguintes notícias veiculadas por jornais de Cascavel e região descrevendo o suicídio de um adolescente interno do Centro, caracterizando, assim, um paradoxo entre o discurso sobre ressocialização ali proferido e a realidade:

"Enforcamento: Centro confirma suicidio de menor em alojamento" - Jornal Gazeta do Paraná, 23/06/08.

"Efeito Dominó: em menos de uma semana, outro interno tenta suicídio" - Jornal Gazeta do Paraná, 30/06/08.

"Interno do Cense de Cascavel tenta suicídio. Essa é a segunda tentativa dentro de uma semana. Um garoto suicidou-se na semana passada.”-Portal Bem Paraná, 30/06/08.

Se o papel funcional da instituição corresponde ao imaginário que seus funcionários dela fazem, como explicar o suicídio desse adolescente e a tentativa de diversos outros? ${ }^{7}$ De acordo com dois funcionários entrevistados do Centro, uma psicóloga e um educador, a responsabilização é toda do(s) adolescente(s), pois para a primeira isso é fruto da extrema dependência química dos meninos; e para o educador, a justificativa do suicídio advém da

\footnotetext{
7 Nas três semanas seguintes ao suicídio do adolescente, houve diversas tentativas da parte de outros meninos; um deles quase morreu. A onda de suicídios na instituição levou a uma série de medidas disciplinares, em que os meninos ficavam algemados, ou com marca-passo, espécie de algema para os pés, sem qualquer objeto que pudesse causar-lhes a morte. Foram retirados os cobertores, as calças compridas, os moletons (era inverno), para que não usassem como instrumento de enforcamento.
} 
incapacidade do adolescente conviver com seus crimes e erros, uma vez que, ao tomarem consciência do que são, do que fizeram, dos sofrimentos que impingiram aos familiares e amigos, a vida torna-se-lhes insuportável. Não acreditamos que tais afirmações sejam processos objetivos e intencionais de mascaramento da realidade, que procuram meramente dissimular as ações do Centro. Todavia, acreditamos que o imaginário desses funcionários está vinculado a práticas de alienação em relação à própria realidade vivenciada na instituição, daí o paradoxo entre as falas dos funcionários e as manchetes de suicídio, por exemplo.

É na distinção ou mesmo contradição entre as construções de sentido - já que uma coisa não leva a outra, ou seja, já que as falas destoam, no mínimo, da prática - e, ao mesmo tempo, na ilusão de unificação do real fragmentado - uma vez que essa concepção de instituição é crível aos funcionários, e não uma 'invenção'maquiavélica -, que funciona o imaginário social. E isso só se dá a partir das condições de produção dos discursos do Centro e de seus funcionários (pois o imaginário se utiliza do simbólico para existir, ao mesmo tempo em que o simbólico pressupõe a capacidade imaginária) e das formações discursivas que lhes correspondem, uma vez que a visão de instituição modelar da América Latina é alicerçada e amparada pelos discursos de ideário educacional, motivador e de protagonismo juvenil, pelo qual o Centro - assim como a política estadual de atendimento à criança e ao adolescente - se vê cercado a partir das falas de seus funcionários.

Contudo, e salientamos a importância de frisar, o imaginário social distingue-se da imaginação individual ou mesmo dos emblemas e da simbolização de massa que subsistem nas diferentes culturas/comunidades. Nesta perspectiva, Ferreira e Eizirik (1994, p.6) nos auxiliam a entender esse ponto de vista ao trazerem o posicionamento de Marx, Durkheim e Max Weber, afirmando que esses reconhecem que as ações humanas não resultam de decisões estritamente racionais; isto é, o que se vive, como se vive, e como se percebe/reflete o que se vive está permanentemente incrustado de representações que estabelecem uma relação orgânica entre homem-homem, homens-natureza, na qual suas (re)(trans)formações são diariamente marcadas pela conformação e/ou (porque podem ser simultâneas) pela confrontação, não como "decorrência" ou como "material de construção" do imaginário social, mas como parte de sua correlação histórico-simbólica. Portanto, "as análises das ideologias, o estudo das correlações entre as estruturas sociais e os sistemas de representações coletivas, o modo como elas abrem para uma instância que assegura a coesão social [é o que] nos apontam para o Imaginário Social.”(FERREIRA \& EIZIRIK, 1984, p.6).

Assim, as práticas sociais dos sujeitos, os processos nos quais estabelecem relações sócio-históricas, suas identificações e seus arranjos coletivos e suas inscrições em determinadas esferas de conhecimento/saberes não resultam de normas, crenças e valores que se "criam" por geração espontânea em determinado espaço/cultura, pois se toda sociedade conta com um sistema de representações cujos sentidos traduzem um sistema de crenças, só podemos entendê-los (tanto as representações, quanto os sentidos que daí se constroem) como instância que legitima a ordem social vigente. Ordem essa que não é harmônica e/ ou consensual, e que por isso é instituída, ao mesmo tempo em que institui, naquilo que Ferreira e Eizirik (1984) denominam de "luta pela hegemonia", isto é, há em toda sociedade um sistema de representações cujos sentidos traduzem crenças e valores que, em última instância, legitimam e/ou transformam a ordem social. É desse modo que as produções de sentidos que circulam na sociedade, e que permitem a regulação de comportamentos, de identificações e de distribuição de papeis sociais, apresentam-se, em sua maioria, como naturalizadas, fazendo crer que as hierarquizações, os processos de dominação e de exclusão e a legitimidade de certas práticas tornem-se verdadeiras aos homens. Isso pode ser explicado a partir do entendimento de que a 'realidade' é vivida real e imaginariamente 


\section{Conexão Letras}

pelos homens, o que possibilita, como vimos acima com Castoriadis (1982), a dialetização ao mesmo tempo dos processos de compreensão e de fabulação. Esses processos autorizam a fundação e legitimação de sistemas simbólicos complexos, que acabam por, muitas vezes, 'proteger' relações de poder estabelecidas, a partir de sistemas de formação de opinião (como as campanhas quase diárias e apelativas da mídia brasileira ao arquitetar a diminuição da maioridade penal), de produções legais (como a legislação deficitária no que se refere às crianças e adolescentes em risco social - e não somente em conflito com a lei) e de coerção (como as diversas violências - físicas e simbólicas - impingidas àqueles que não se ajustam aos modelos pré-estabelecidos).

É por isso que, mais uma vez, apoiamo-nos em Castoriadis, que nos diz:

Tudo que se nos apresenta no mundo sócio-histórico está indissoluvelmente entrelaçado com o simbólico. Não que se esgote nele. Os atos reais, individuais ou coletivos - o trabalho, o consumo, a guerra, o amor, a natalidade - os inumeráveis produtos materiais sem os quais nenhuma sociedade poderia viver um só momento, não são (nem sempre, não diretamente) símbolos. Mas uns e outros são impossíveis fora de uma rede simbólica.(1982, p.142).

Compreendendo essa impossibilidade da produção de sentidos fora dessa rede simbólica, é que percebemos que a Análise de Discurso diferencia-se de outros ramos da lingüística e das ciências sociais, por exemplo, ao tratar das questões de sentido, da linguagem, dos sujeitos e do efeito do simbólico. Não se trabalha, em AD, simplesmente com os conteúdos ideológicos e/ou sociais, mas com os processos de constituição da linguagem e da ideologia. Por isso, não há como formalizar o sentido, prendendo-o à estrutura lingüística, nem mesmo como acrescentar as particularidades sócio-culturais ao estudo da língua. Sendo uma teoria de entremeio, a AD assume-se inteiramente comprometida com a múltipla constituição do simbólico, do político e do ideológico. Nesse ínterim, a história apresenta-se como condição fundante do processo discursivo, sem a qual não se produziriam ou circulariam os sentidos. O social é também fator determinante nos processos simbólicos, especialmente quando tratamos dos modos de determinação. Contudo, esse social não se caracteriza, como dissemos acima, na quantificação de dados empíricos sobre a condição do sujeito, mas na relação do real fragmentado e do fluxo imaginário que amalgamam sentidos e práticas. Para Orlandi, isso pode também ser explicado em:

\footnotetext{
"Quanto ao social, não são os traços sociológicos empíricos - classe social, idade, sexo, profissão - mas as formações imaginárias que se constituem a partir das relações sociais que funcionam no discurso: a imagem que se faz de um pai, de um operário, de um presidente, etc. Há em toda língua mecanismos de projeção que permitem passar da situação sociologicamente descritível para a posição dos sujeitos discursivamente significativa" (1994, p.56)
}

As imagens que se fazem, então, do adolescente internado, pelos funcionários do Centro, como posições de sujeito discursivamente significativas no interior de determinada FD, se constroem também a partir da imagem que estes têm da instituição. E essas imagens só podem realmente construir-se como ordenação de uma pluralidade na projeção que se faz de si e do outro nas relações sociais. Se um é o sujeito que provê, que auxilia, que encaminha, que ressocializa; o outro não pode ser outra coisa senão o necessitado, o deficiente, o desajustado. Perpetuar essa imagem de um sujeito que não se ajusta aos modelos sociais - ou por culpa própria, como nos documentos pré-ECA, ou por privações de diversas 
ordens, como manda a cartilha do politicamente correto - parece justificar a existência de instituições como o Centro e de seus funcionários, justificativa essa que se efetiva a partir do conjunto de significações que constituem o imaginário, real, dos que trabalham na instituição. É dessa efetivação do imaginário que nos fala Córdova, na citação abaixo:

\begin{abstract}
"O imaginário efetivo, ou imaginado, é o produto do imaginário radical e se constitui como a profusão ou, na linguagem do autor [Castoriadis], o magma de significações imaginárias sociais atuantes, operantes, 'em uso', cada vez, por uma determinada sociedade. Cada sociedade se caracteriza por um conjunto de significações que indicam a sua esseidade, ou seja, the dão a sua identidade e a sua unidade. É por meio dessas significações criadas que os homens percebem, vivem, pensam e agem. E essas significações, instituições, são, antes de mais nada, significações operantes, efetivas, ainda que irrefletidas, inconscientes. Esse imaginário efetivo em forma de significações, entretanto, é real (não imaginário!), e até mais real que o 'real'.' (grifos do autor - 1994, p.29)
\end{abstract}

Para o imaginário dos funcionários do Centro, a 'realidade' dos meninos internados é que eles necessitam de intervenção para poderem viver em sociedade, e essa intervenção é dada por uma instituição de pessoas técnicas, especializadas, que reconhecem as debilidades desses adolescentes e tentam trabalhá-las no sentido de que esses as possam superar. Esse real construído a partir das diversas formações imaginárias que impregnam o universo da instituição, e o seu redor, ancora-se também fortemente na questão da especialização e na divisão dos trabalhos. Somente a equipe técnica tem o direito de saber o delito que o adolescente cometeu; somente os educadores sociais podem fazer o acompanhamento diário dos meninos; o psicólogo é chamado para resolver os assuntos emocionais; os educadores sociais é que intervêm nos momentos de conflito. Essa divisão do trabalho, por estar implicada na constituição do imaginário social de cada um dos funcionários, e ao delinear os modos de determinação específico de quem é esse adolescente e quais são suas condições de vida, segmenta as ações do Centro, reforçando os questionamentos ao trabalho de socioeducação ali realizados.

\title{
Considerações Finais
}

A complexidade das questões que giram em torno deste sujeito de nossa pesquisa é tamanha que sabemos não ser possível, nem de longe, conseguirmos abarcar os principais aspectos que lhe moldam o "espírito e as ações". Entretanto, no delineamento das ações de segregação e estigmatização deste jovem, observamos imaginários que os descrevem ora como sujeitos desestruturados sócio e emocionalmente, que necessitam de atenção e carinho, ora como agressores que precisam de punição e de correção. No amálgama desses imaginários encontra-se a instituição de socioeducação, que se apresenta como a "redentora" para as mais diferenciadas visões, mas que, como instituição totalizante, não traz mudanças significativas para a diminuição da criminalidade juvenil.

\section{Referências}

BARBIER, R. Sobre o Imaginário. In: Revista Em Aberto, Brasília, ano 14, n.61, jan./ mar. 1994.

CASTORIADIS, Cornelius. A instituição imaginária da sociedade. $6^{\mathrm{a}}$ ed. Rio de Janeiro: Paz e Terra, 1982. 


\section{Conexão Letras}

CÓRDOVA, R.A. Imaginário Social e Educação. In: Revista Em Aberto, Brasília, ano 14, n.61, jan./mar. 1994.

COURTINE, Jean-Jacques. Metamorfose do discurso político: as derivas da fala pública. São Carlos: Claraluz, 2006

FERREIRA, N.T. \& EIZIRIK, M.F. Imaginário Social e Educação: revendo a escola. In: Revista Em Aberto, Brasília, ano 14, n.61, jan./mar. 1994.

GOFFMAN, Erving. Estigma: notas sobre a manipulação da identidade deteriorada. Rio de Janeiro: Zahar Editores, 1975. Trad. Márcia Bandeira de Mello Leite Nunes. HAROCHE, Claudine. Fazer dizer, querer dizer. Editora Hucitec: São Paulo, 1992. Trad.Eni P. Orlandi et al.

ORLANDI, Eni Puccinelli. Discurso, imaginário social e conhecimento. In: Revista Em Aberto, Brasília, ano 14, n.61, jan./mar. 1994.

PÊCHEUX, Michel. Análise Automática do Discurso (AAD-69). In: GADET, F. \& HAK, T. (orgs.) Por uma análise automática do discurso: uma introdução à obra de Michel Pêcheux. 3.ed. Campinas, SP: Editora da Unicamp, 1997. Trad. Eni P. Orlandi 